$\underline{\xi}=-1$

\title{
Anti-inflammatory activity of craterostigma pumilum (hochst) is associated with hyperalgesia
}

\author{
Mwonjoria K. John ${ }^{1 *}$, Umar Aliyu ${ }^{2}$, Juma K. Kevin ${ }^{1}$, Kahiga M. Titus ${ }^{3}$, Ngugi M. Piero ${ }^{1}$, Mburu David ${ }^{1}$, \\ Wanyonyi W. Alphonse ${ }^{4}$, Githinji G. Charles ${ }^{5}$, Ngeranwa N. Joseph ${ }^{1}$ \\ ${ }^{I}$ Department of Biochemistry and biotechnology; Kenyatta University, Kenya \\ ${ }^{2}$ Department of Biological Sciences, Bauchi State University, Nigeria \\ ${ }^{3}$ Department Pharmacy and complementally medicine; Kenyatta University, Kenya \\ ${ }^{4}$ Department of Chemistry; Kenyatta University, Kenya \\ ${ }^{5}$ Department of Medical physiology; University of Nairobi, Kenya \\ *Corresponding author E-mail: jkmmaina@gmail.com
}

\begin{abstract}
Inflammation and pain are ubiquitous signs and symptoms of a large number of ailments affecting humanity. There are equally as many methods and substances that are used as remedies for the conditions. Examples of remedies used include herbal extracts such those of genus Craterostigma among others. In Kenya, some plants from this genus are used as folklore remedy for toothache, joint and muscle pains. Interestingly, in spite of their use, there is no scientific study that has been instituted to evaluate their efficacy. The current study evaluated the anti-inflammatory and antinociceptive effect of both dichloromethane (DCM) and aqueous extract of Craterostigma pumilum using animal models. The anti-inflammatory and antinociceptive effect assays were carried out using formalin induced pedal edema and pain test respectively in white Wister rats. The phytochemical profile of the plant extract was carried out using standard procedures. Both DCM and aqueous extracts exhibited highly significant anti-inflammatory $(p<0.001)$ effects but no antinociceptive effects. However, the DCM extract showed a very significant $(\mathrm{p}<0.001)$ hyperalgesia. The study renders support to folklore use of the plant for inflammation however it recommends incorporation of an analgesic remedy in the process.
\end{abstract}

Keywords: Craterostigma; Pumilum; Inflammation; Hyperalgesia; Flavonoids.

\section{Introduction}

Pain and inflammation are hallmark of disease, it is for this reason that many attempts have been made throughout the centuries to find appropriate remedies for these conditions. Besides the common analgesic and anti-inflammatory drugs used in management of these conditions, several other methods are used for the same purpose which include use of extracts of plant parts. Examples of herbs used include Craterostigma pumilum (Hochst) or Nairobi violet, a small perennial herb that belongs to figwort family Scrophulariaceae (Hepper, 1990). The herb is a member of a group referred to as resurrection plants that can tolerate loss of water up to $98 \%$ of its content and yet return to active metabolism and growth within hours after rehydration. It is found in seasonally water filled rock pools, inselbergs, and heavy metal containing soils (Bartels, 2001). The roots are chewed by humans and tastes like a sweet carrot (Bussmann et al., 2011). It is used in treatment of tooth ache where it is chewed and retained in the mouth for some time (Kokwaro, 1993), a related plant Craterostigma plantagenium is used in management of joint and muscle pains (Bussman et al., 2006). Craterostigma spp. contains raffinose series oligosaccharides, 2-octulose, sucrose etc (Norwood et al., 2000). There are little or no scientific reports on effects of this plant on pain and inflammation and its phytochemical composition. The aim of this study was to evaluate the effects of this plant extracts on pain and inflammation and to determine the types of phytochemical present.

\section{Materials and methods}

\subsection{Plants materials}

\subsubsection{Collection and pre-treatment of plant materials}

Fresh Craterostigma pumilum whole plants were collected in 2013 from Sengera region of Laikipia County during the day. They were identified and specimens deposited in the University of Nairobi herbarium, 2013 / JM03. They were air dried in a room away from direct sunlight for one and half months then ground into a fine powder using a gliding mill.

\subsubsection{Extraction with dichloromethane}

About 100 grams of the powder was weighed and was extracted with dichloromethane (DCM) for 72 hours. First it was soaked in DCM, stirred and allowed to stand for two hours. It was decanted and the powder soaked again in DCM and allowed to stand for 24 hours at room temperature before decanting. The procedure was repeated twice in the next 48 hours. The supernatant obtained was filtered using Whatman No.1 filter paper. The extracts were then dried using a rotary evaporator and placed in specimen bottles with seal. The extract which weighed $1.63 \mathrm{~g}$ was placed in universal bottles and stored in a cool dry place in the laboratory. 


\subsubsection{Extraction with water}

About 200 grams of the powder was soaked in distilled water in a conical flask stirred and placed in a water bath at $60^{\circ} \mathrm{C}$ for 4 hours. It was the removed filtered using Whatman No. 1 filter paper. The filtrate was then freeze dried to obtain a powder which weighed about $21.26 \mathrm{~g}$. The extracts were put in air tight containers and stored in the refrigerator at $4^{\circ} \mathrm{C}$ until further use.

\subsection{Experimental animals}

White Wister rats 150 to 200 grams and in groups $(n=5)$ were used for both antinociceptive and anti-inflammatory assay. All the animals were placed in cages in rooms maintained at between 20 to 25 degrees centigrade and allowed to acclimatize for seven days before the start of the experiments. Standard commercial diet and water was provided ad libitum. A 12 hour day light/dark cycle was maintained throughout the period. All the in vivo experiments were carried out as per the guidelines for care and use of laboratory animals (Wolfensohn \& Lloyd, 1998).

\subsection{Drugs and chemicals}

The following drugs and chemicals were used in the study; diclofenac sodium, formalin, morphine, dimethyl sulfoxide (DMSO).

\subsection{Anti-inflammatory activity assay}

Formalin induced paw edema with some modification was used as a model for acute inflammation (Hunskaar\& Hole, 1985; Rosland et al., 1990). It was used to assess the anti-inflammatory affects of C. pumilum. One set $(n=5)$ of white Wister rats $(150-200$ grams $)$ received intraperitonial injection of 25,50 and $100 \mathrm{mg} / \mathrm{kg}$ doses of DCM extract, $15 \mathrm{mg}$ diclofenac sodium and the vehicle $(30 \%$ DMSO in normal saline), while another received 25, 50 and 100 $\mathrm{mg}$ doses of aqueous extract of the herb and $15 \mathrm{mg}$ diclofenac sodium and the vehicle (normal saline), orally. They were then allowed to rest for 30 minutes to allow for drug distribution. After 30 minutes, inflammation was induced in the rats by injecting 50 $\mu \mathrm{g}$ of $5 \%$ formalin in the sub-plantar region of the left hind paw. The diameter of the paw was measured using digital calipers. The initial paw diameter was taken before formalin injection and the rest every 30 minutes for four hours. The difference between these initial values and the readings at subsequent times was quantified as the hind paw edema in rats and they were compared with the vehicle treated groups.

\subsection{Antinociceptive activity assay}

Table 1: Effect of DCM Extract of C. Pumilum on Formalin Induced Change in Paw Edema in Rats as A Function of Time

\begin{tabular}{|c|c|c|c|c|c|c|c|}
\hline \multicolumn{8}{|c|}{ Time in minutes } \\
\hline Treatment & $0 \mathrm{~min}$ & $30 \mathrm{~min}$ & $60 \mathrm{~min}$ & $90 \mathrm{~min}$ & $120 \mathrm{~min}$ & $180 \mathrm{~min}$ & $240 \mathrm{~min}$ \\
\hline $25 \mathrm{mg}$ & 0 & $1.76 \pm 0.13$ & $2.25 \pm 0.9$ & $2.16 \pm 0.16$ & $2.15 \pm 0.21$ & $2.15 \pm 0.21 * *$ & $2.27 \pm 0.36$ \\
\hline $50 \mathrm{mg}$ & 0 & $1.17 \pm 0.14 * *$ & $1.2 \pm 0.11 * *$ & $1.17 \pm 0.23 * *$ & $1.17 \pm 0.16^{*}$ & $1.18 \pm 0.1 * *$ & $1.29 \pm 0.1 * *$ \\
\hline $100 \mathrm{mg}$ & 0 & $1.48 \pm 0.11$ & $1.52 \pm 0.19 *$ & $1.55 \pm 0.13^{*}$ & $1.05 \pm 0.17 * *$ & $0.96 \pm 0.22 * *$ & $0.84 \pm 0.15^{* *}$ \\
\hline Diclofenac & 0 & $2.09 \pm 0.09$ & $2.43 \pm 0.1$ & $2.13 \pm 0.16$ & $1.94 \pm 0.12$ & $1.7 \pm 0.08 * *$ & $2.51 \pm 0.06$ \\
\hline Vehicle & 0 & $2.15 \pm 0.19$ & $2.75 \pm 0.17$ & $2.86 \pm 0.11$ & $3.37 \pm 0.19$ & $3.35 \pm 0.16$ & $3.09 \pm 0.2$ \\
\hline Formalin & 0 & $2.83 \pm 0.34$ & $3.29 \pm 0.41$ & $3.25 \pm 0.43$ & $3.58 \pm 0.38$ & $3.56 \pm 0.38$ & $3.23 \pm 0.09$ \\
\hline
\end{tabular}

Values in the table represent change in diameter in millimeters. $(* \mathrm{p}<0.05 ; * * \mathrm{p}<0.001)$.

The antinociceptive effects of the extracts were evaluated using the formalin test as described in (Hunskaar\& Hole, 1985; Rosland et al., 1990; Tjølsen et al., 1992). The left hind paw that was to be injected with formalin was marked with permanent marker pen. Pain was induced by administration of $50 \mu 1$ of $5 \%$ formalin in sub-plantar region of the paw using a 30 gauge needle (Rosland et al., 1990). The white Wister rats in groups $(n=5)$ weighing 150 $200 \mathrm{~g}$ received the three doses of C. pumilum DCM extracts, 15 $\mathrm{mg}$ of injectable diclofenac sodium, $5 \mathrm{mg}$ morphine and vehicle (30\% DMSO in normal saline) intraperitonially while the doses of the aqueous extracts of the herbs, oral formulation of diclofenac and vehicle (normal saline) was administered orally. All the treatments were administered 30 minutes prior to formalin injection.

The animals were individually placed in transparent plexiglass cage observation chamber and two mirrors were placed behind and on the side of the cage for ease of visualizing the paws from all sides. The amount of time spent lifting, biting, flinching and licking the injected paw was considered as indicator of pain and was be recorded for 30 minutes after the formalin injection. Early phase of nociception was measured between 0-5 minutes while late phase took place between 15-30 minutes after formalin injection. The early phase represents neurogenic pain while the late phase is due to inflammatory pain response and central sensitization (Hunskaar\& Hole, 1987; Rosland et al., 1990; McNamara et al., 2007).

\subsection{Data analysis}

The data obtained for each set of experiment was pooled as a mean, standard deviation and standard errors of the mean. One way Anova and Scheffé post hoc test was used to compare the test and control group values. A value of $p<0.05$ was considered to be the limit of significance.

\section{Results}

Evaluation of analgesic or antinociceptive effect of the herbs extract was carried out using formalin test. The pull test (a sensory
motor test) was used to evaluate the muscle relaxing effect of the herb extracts. It separates muscle relaxation from sedation, catalepsy and catatonia (sensory motor impairment) (Deacon \& Gardner, 1984). Only the animals that showed no sensory motor imwere used for subsequent experiments.

\subsubsection{Formalin test}




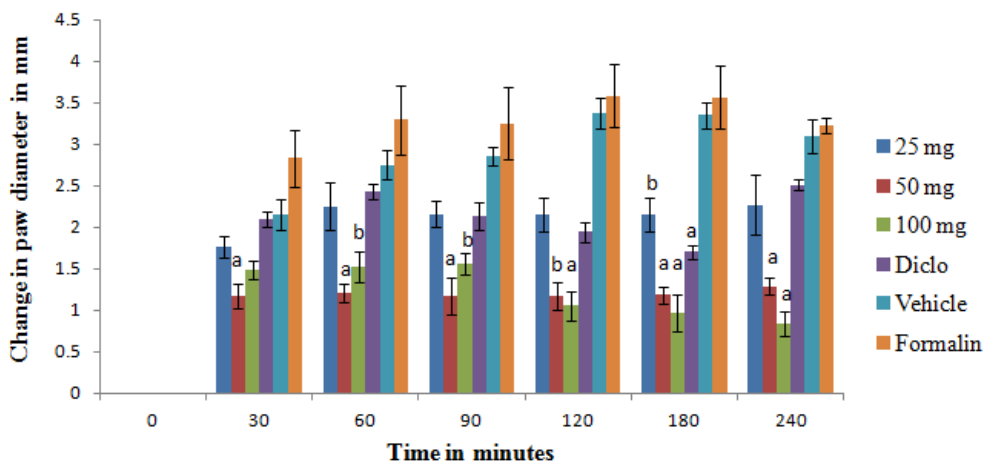

Fig. 1:Anti-Inflammatory Effect of DCM Extract of C. Pumilum.

Effect of DCM extract of C. pumilum on formalin induced change in paw diameter in rats as a function of time. The $25 \mathrm{mg}$ showed significant $(\mathrm{p}<0.05)$ effect at 180 minutes, while both the 50 and $100 \mathrm{mg}$ doses more varied activity. $\left({ }^{\mathrm{a}} \mathrm{p}<0.001 ;{ }^{\mathrm{b}} \mathrm{p}<0.05\right)$.

Table 2: Effect of Aqueous Extract of C. Pumilum on Formalin Induced Change in Paw Edema in Rats as A Function of Time.

\begin{tabular}{|c|c|c|c|c|c|c|c|}
\hline \multicolumn{8}{|c|}{ Time in minutes } \\
\hline Treatment & $0 \mathrm{~min}$ & $30 \mathrm{~min}$ & $60 \mathrm{~min}$ & $90 \mathrm{~min}$ & $120 \mathrm{~min}$ & $180 \mathrm{~min}$ & $240 \min$ \\
\hline $25 \mathrm{mg}$ & 0 & $1.76 \pm 0.18$ & $2.17 \pm 0.28$ & $2.37 \pm 0.53$ & $1.94 \pm 0.21$ & $2.04 \pm 0.39$ & $2.19 \pm 0.33$ \\
\hline $50 \mathrm{mg}$ & 0 & $1.29 \pm 0.06^{*}$ & $1.22 \pm 0.06^{*}$ & $1.29 \pm 0.1$ & $1.19 \pm 0.13 *$ & $1.05 \pm 0.15$ & $1.13 \pm 0.17 *$ \\
\hline $100 \mathrm{mg}$ & 0 & $1.16 \pm 0.11 * *$ & $1.18 \pm 0.21 * *$ & $1.32 \pm 0.12$ & $1.17 \pm 0.17 * *$ & $1.08 \pm 0.19 *$ & $0.78 \pm 0.22 *$ \\
\hline Diclofenac & 0 & $1.45 \pm 0.18^{*}$ & $1.14 \pm 0.19 * *$ & $0.836 \pm 0.26^{*}$ & $0.65 \pm 0.19 * *$ & $0.55 \pm 0.26^{* *}$ & $0.43 \pm 0.18^{* *}$ \\
\hline Vehicle & 0 & $2.26 \pm 0.19$ & $2.52 \pm 0.17$ & $2.52 \pm 0.11$ & $2.4 \pm 0.16$ & $2.33 \pm 0.07$ & $2.2 \pm 0.22$ \\
\hline Formalin & 0 & $2.44 \pm 0.18$ & $2.82 \pm 0.27$ & $2.84 \pm 0.25$ & $2.8 \pm 0.29$ & $2.75 \pm 0.23$ & $2.69 \pm 0.22$ \\
\hline
\end{tabular}

Values in the table represent change in diameter in millimeters. $(* \mathrm{p}<0.05 ; * * \mathrm{p}<0.001)$

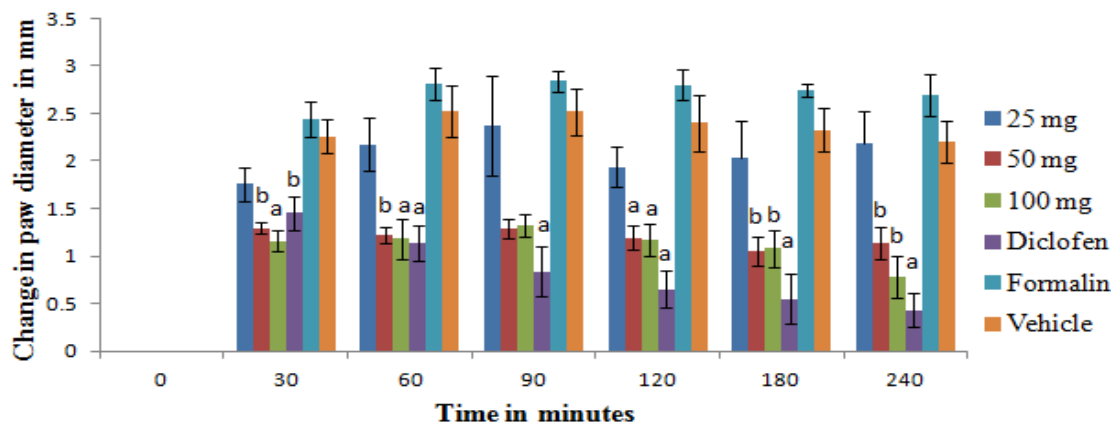

Fig. 2: Anti-Inflammatory Effect of Aqueous Extract of C. Pumilum.

Effect of aqueous extract of C. pumilum on formalin induced change in paw diameter in rats as a function of time. The 50 and $100 \mathrm{mg}$ doses of extract exhibited significant $(p<0.05)$ anti-inflammatory effect. $\left({ }^{a} p<0.001 ;{ }^{b} p<0.001\right)$

Table 3: Effect of DCM Extract of C. Pumilum on Formalin Induced Nociception in Rats

\begin{tabular}{llc} 
& Table 3: Effect of DCM Extract of C. Pumilum on Formalin Induced Nociception in Rats & Phase II \\
\hline Treatment & Phase I & $725 \pm 29.92$ \\
\hline $25 \mathrm{mg}$ & $269.8 \pm 1.85$ & $556.8 \pm 2.64$ \\
$50 \mathrm{mg}$ & $269.6 \pm 3.26$ & $736.6 \pm 19.74$ \\
$100 \mathrm{mg}$ & $268 . \pm 63.31$ & $84 \pm 19.8 * *$ \\
Diclofenac sodium & $132 \pm 12 *$ & $312 \pm 24.6$ \\
Vehicle & $204 \pm 30.6$ & $336 \pm 40.69$ \\
Formalin & $260 \pm 12.65$ & $23.6 \pm 3.08 * *$ \\
Morphine & $42.4 \pm 7.49 * *$ & \\
\hline
\end{tabular}

$(* \mathrm{p}<0.05 ; * * \mathrm{p}<0.001)$

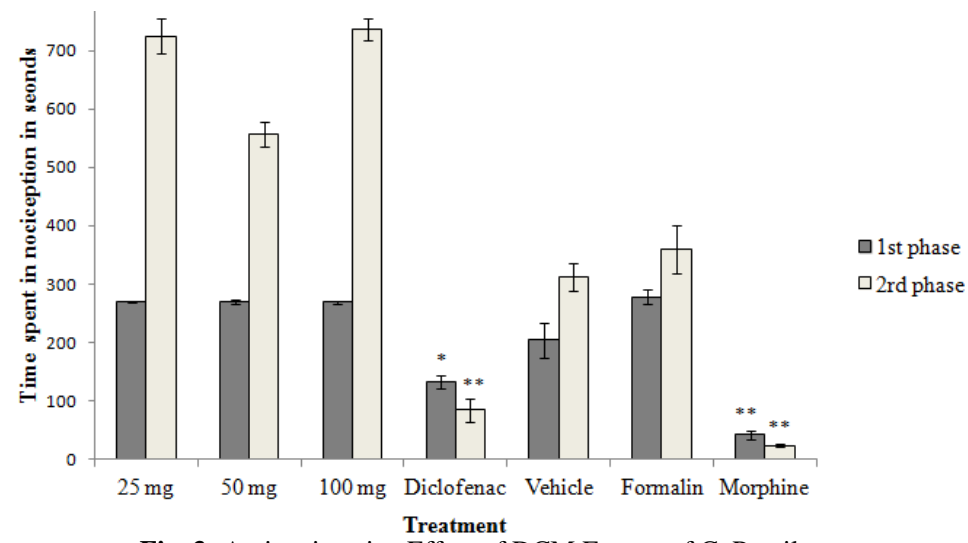

Fig. 3: Antinociceptive Effect of DCM Extract of C. Pumilum. 
Effect of DCM extract of C. pumilum on formalin induced nociception in rat's effect of $25,50 \& 100 \mathrm{mg}$ are exaggerated.

Table 4: Effect of DCM Extract of C. Pumilum on Formalin Induced Nociception in Rats

\begin{tabular}{lll}
\hline Treatment & Phase I & Phase II \\
\hline $25 \mathrm{mg}$ & $245.0 \pm 10.69$ & $512.4 \pm 68.21$ \\
$50 \mathrm{mg}$ & $241.2 \pm 11.32$ & $311.8 \pm 11.67$ \\
$100 \mathrm{mg}$ & $243.4 \pm 9.36$ & $339.4 \pm 36.94$ \\
Diclofenac sodium & $228.6 \pm 9.43 *$ & $184.8 \pm 17.69 * *$ \\
Vehicle & $282.8 \pm 3.61$ & $452.0 \pm 36.14$ \\
Formalin & $252.0 \pm 12$ & $336.0 \pm 40.60$ \\
Morphine & $42.4 \pm 7.49 * *$ & $23.6 \pm 3.08 * *$ \\
\hline
\end{tabular}

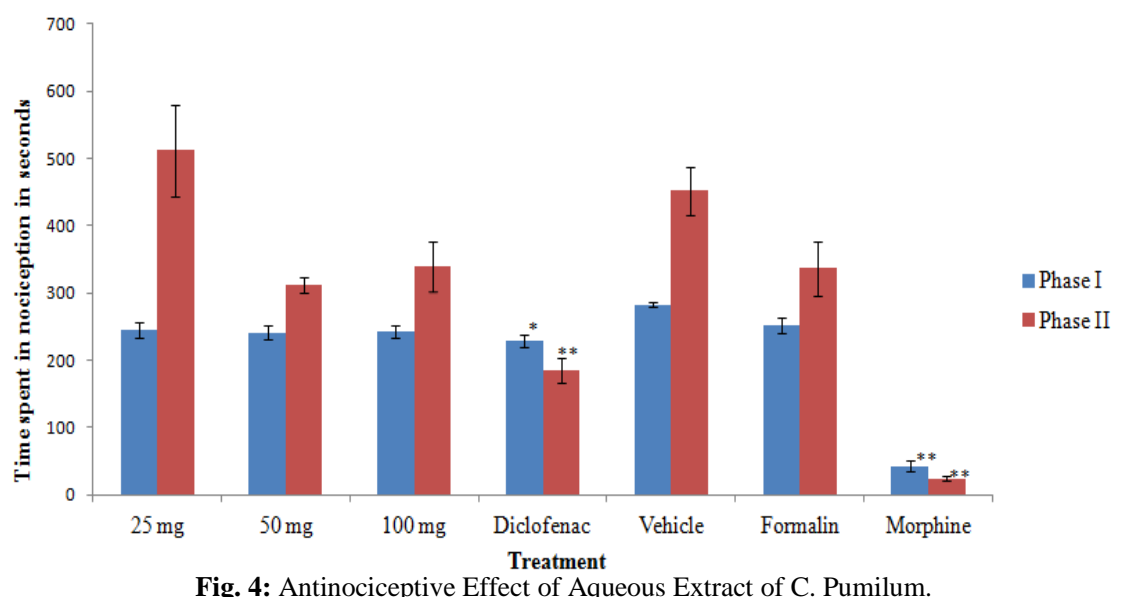

Fig. 4: Antinociceptive Effect of Aqueous Extract of C. Pumilum.

Effect of aqueous extract of C. pumilum on formalin induced nociception in rats. The various doses of the herbal extract had no significant inhibitory effect on nociceptive activity.

Table 5: Some Groups of Phytochemicals Present in C. Pumilum

\begin{tabular}{lc}
\hline Phytochemicals & Status \\
\hline Flavonoids & +++ \\
Alkaloids & - \\
Saponins & + \\
Terpenes & + \\
Phenolics & + \\
Tannins & ++ \\
Glycosides & + \\
\hline
\end{tabular}

+ Present; - Absent.

\section{Discussion}

Anti-inflammatory effects, The $25 \mathrm{mg}$ dose of DCM extract of C. pumilum exhibited significant $(\mathrm{p}<0.05)$ anti-edema effect at 180 minutes following formalin injection (Fig.1; Table 1) with the other doses of the herb showing effect in subsequent times. However it, $(25 \mathrm{mg})$ failed to show similar activity in the aqueous phase unlike the other doses (Fig.2; Table 2). The phlogistic effect of formalin and carrageenan is a well-established fact. Injections of either of the two substances induce similar local inflammatory reactions, though formalin induces more persistent reaction (Goulart et al., 2005). Administration of low doses of formalin induces edema mainly due to neurogenic inflammation mediated by peptides especially substance P. Nevertheless, at higher doses, the edema effect is mainly due to release of substance $\mathrm{P}$, serotonin, prostanoids and histamine. These substances increase capillary permeability resulting in exudation of fluid in the interstitial space thereby causing edema. Surprisingly, bradykinin plays an insignificant role in this process in spite of its supposedly stimulatory activity on the nociceptive afferent neurons. It is believed that this phenomenon arises from the variation in the stimulation threshold of the nociceptive neurons and endothelium or perhaps due to formation of kinins in proximity to the neurons (Damas\&Liégois, 1999).

There are several drugs used in alleviation of inflammatory conditions that include NSAIDS e.g. aspirin and diclofenac. They inhibit prostaglandin synthesis (Vane, 2000) and steroids that target migration and ultimately degranulation of leukocytes (Farsky et al., 1995). In this study, the edema was obliterated by prior admin- istration of $15 \mathrm{mg}$ of diclofenac sodium 30 minutes prior to injection with formalin. In the subsequent experiments, various doses of both DCM and aqueous extract of C. pumilum were administered.

The DCM extract represents the less polar fraction while the aqueous extract contains the most polar fraction. Hence it is probable that both the polar and non-polar portions of the herb extracts contained relatively active metabolites with anti-inflammatory effects. The activity of these metabolites was comparable to the effect of diclofenac (Fig $1 \& 2$ ). The extract contained a large amount of flavonoids among other secondary metabolites (Table 5). The flavonoids were shown to exert anti-inflammatory effect that involved inhibition of arachidonic acid metabolism (Ferrandiz\&Alcaraz, 1991). Therefore it is highly probable that the anti-inflammatory effects observed may be due to these phytochemicals individually or combined with others. C. pumilum showed elevate anti-inflammatory activity therefore it is likely to a good source of an anti-inflammatory remedy hence more investigation is needed to isolate elucidate and determine the activity as well as the toxicity of the metabolite(s) responsible for this activity. However its DCM extract highly elevated the agonizing or chronic phase of nociception (Fig. 3; Table 3) but the aqueous fraction had no effect on nociception which may indicate that the crude DCM extract contained secondary metabolite(s) that may have been responsible for this effect. Therefore more studies require to be done targeting both the mechanism and toxicity and applicatability of these plant metabolites in research and perhaps use as a substitute for capsaicin as an agonist in vanelloid receptor studies and perhaps as a component of tear gas during riot control. 


\section{Conclusion}

In this study, C. pumilum obliterated edema development but at the same time aggravated the nociceptive activity. Phytochemical analysis showed that plant extract contained several groups of metabolites with exception of alkaloids. Therefore one or several of these metabolites present may have been responsible for the hyperalgesic and anti-inflammatory effects seen in the study. Hence, though the plant extract displayed splendid antiinflammatory effect, it is of limited use in analgesia. Therefore, this study recommends that the folklore practitioners should take heed and include an analgesic when administering the herbal in management of inflammatory diseases.

\section{Acknowledgements}

Authors wish to thank Kenya National Commission for Science Technology and Innovation (NACOSTI) for supporting this work through Grant No.; NCST/ST\&I/RCD/4th Call PhD/102,

Kenyatta University for availing laboratory space and apparatus and the following persons Mr Mutiso University of Nairobi, Mr James Adino, Mr Daniel G. Mwaniki, Mr Kariuki and Mr Wicliff Wenwa Kenyatta University for technical support.

The author declares there is no conflict of interest.

\section{References}

[1] Balick M, Duke J, Kaptchuk T, McCaleb RS, Pavek R, Pellerin C, Reed J, SwyersJP. (1995). Overview: History of herbal medicines: Alternative medicine expanding medical horizons: A Report to the National Institutes of Health on Alternative Medical Systems and Practices in the United States. Diane Publishing Company, 183-206.

[2] Barbosa-Filho JM, Piuvezam MR, Moura MD, Silva MS, Lima KVB, da-Cunha EVL et al. (2006). Anti-inflammatory activity of alkaloids: A twenty-century review. RevistaBrasileira de Farmacognosia, 16(1): 109-139. http://dx.doi.org/10.1590/S0102695X2006000100020.

[3] Bartels D \&Salamini F. (2001). Desiccation tolerance in the resurrection plant craterostigma plantagineum. A contribution to the study of drought tolerance at the molecular level. Plant Physiology, 127(4): 1346-1353. http://dx.doi.org/10.1104/pp.010765.

[4] Bianchi G, Gamba A, Murelli C, Salamini F, Bartels D. (1991) Novel carbohydrate metabolism in the resurrection plant Craterostigma plantagineum. The Plant Journal, 1(3): 355-359. http://dx.doi.org/10.1046/j.1365-313X.1991.t01-11-00999.x.

[5] Bussmann R W, Swartzinsky P, Worede A, Evangelista P. (2011). Plant use in Odo-Bulu and Demaro. Bale region, Ethiopia. Journal of ethnobiology and ethnomedicine, 7(1): 1 http://dx.doi.org/10.1186/1746-4269-7-28.

[6] Bussmann RW, Gilbreath GG, Solio J, Lutura M, Rutuluo R, Kunguru K et al. (2006). Plant use of the Maasai of Sekani Valley, Maasai Mara, Kenya. Journal of Ethnobiology and Ethnomedicine. 2(1):1-16. http://dx.doi.org/10.1186/1746-4269-2-1.

[7] DamasJ\&Liegeois JF. (1999). the inflammatory reaction induced by formalin in the rat paw. Naunyn-Schmiedeberg's Archives of Pharmacology, 359(3): 220-227. http://dx.doi.org/10.1007/PL00005345.

[8] Deacon RMJ \& Gardner CR. (1984). The pull-up test in rats: a simple method for evaluating muscle relaxation. Journal of Pharmacological Methods, 11(2): 119-124. http://dx.doi.org/10.1016/01605402(84)90021-4.

[9] Dubuisson D \& Dennis SG. (1978). the formalin test: a quantitative study of the analgesic effects of morphine, meperidine, and brain stem stimulation in rats and cats. Pain, 4, 161-174. http://dx.doi.org/10.1016/0304-3959(77)90130-0.

[10] Farsky SP, Sannomiya P, Garcia-Leme J. (1995). Secreted glucocorticoids regulate leukocyte-endothelial interactions in inflammation. A direct vital microscopic study. Journal of leukocyte biology, 57(3): 379-386.

[11] Ferrandiz ML \&Alcaraz M J. (1991). Anti-inflammatory activity and inhibition of arachidonic acid metabolism by flavonoids. Agents and Actions, 32(3-4): 283-288. http://dx.doi.org/10.1007/BF01980887.

[12] Goulart AC, Correia F. A, Sousa SC, Luz JG. (2005). Study of the inflammatory process induced by injection of carrageenan or for- malin in the rat temporo-mandibular joint. Brazilian oral Research, 19(2): $\quad 99-105 . \quad$ http://dx.doi.org/10.1590/S180683242005000200005 .

[13] Hepper FN (1990). Craterostigma, Flora Zambesiaca 8(2) 53-56

[14] Higgs GA, Eakins KE, Mugridge KG, Moncada S. (1980). The effects of non-steroid anti-inflammatory drugs on leukocyte migration in carrageenin-induced inflammation. European Journal of Pharmacology, 66(1): 81-86. http://dx.doi.org/10.1016/00142999(80)90297-6.

[15] Hunskaar S \& Hole K. (1987). The formalin test in mice: dissociation between inflammatory and non-inflammatory pain. Pain 30(1):103-114. http://dx.doi.org/10.1016/0304-3959(87)90088-1.

[16] Hunskaar S, Fasmer OB, Hole K. (1985). Formalin test in mice, a useful technique for evaluating mild analgesics. Journal of Neuroscience Methods, 14(1): 69-76. http://dx.doi.org/10.1016/01650270(85)90116-5.

[17] Kokwaro JO. (1993). Medicinal plants of East Africa. 2rd ed. East African literature bureau. Nairobi. 222-223.

[18] McNamara CR, Mandel-Brehm J, Bautista DM, Siemens J, Deranian KL, Zhao M et al. (2007). TRPA1 mediates formalin-induced pain. Proceedings of the National Academy of Sciences, 104(33): 13525-13530. http://dx.doi.org/10.1073/pnas.0705924104.

[19] Norwood M, Truesdale MR, Richter A, Scott P. (2000). Photosynthetic carbohydrate metabolism in the resurrection plant Craterostigma plantagineum. Journal of Experimental Botany, 51(343): 159-165. http://dx.doi.org/10.1093/jexbot/51.343.159.

[20] Rosland JH, Tjølsen A, Mæhle B, Hole K. (1990). The formalin test in mice: effect of formalin concentration. Pain, 42(2): 235-242. http://dx.doi.org/10.1016/0304-3959(90)91167-H

[21] Smith G, Bertone AL, Kaeding C, Simmons E J, Apostoles, S. (1998). Anti-inflammatory effects of topically applied dimethyl sulfoxide gel on endotoxin-induced synovitis in horses. American Journal of Veterinary Research, 59(9): 1149-1152.

[22] Souto AL, Tavares JF, da Silva MS, Diniz MDFFM, de AthaydeFilho PF, Barbosa Filho JM. (2011). Anti-inflammatory activity of alkaloids: an update from 2000 to 2010. Molecules, 16(10): 85158534. http://dx.doi.org/10.3390/molecules16108515.

[23] Tjølsen A, Berge OG., Hunskaar S, Rosland JH, Hole K. (1992). The formalin test: an evaluation of the method. Pain, 51(1): 5-17. http://dx.doi.org/10.1016/0304-3959(92)90003-T.

[24] Vane J. (2000). Aspirin and other anti-inflammatory drugs. Thorax, 55(2): S3-S9. http://dx.doi.org/10.1136/thorax.55.suppl 2.S3.

[25] Wolfensohn S \& Lloyd M. (1998). Small laboratory animals. Handbook of laboratory animal management and Welfare, 2rd ed. Blackwell Science, London, England, 169-217. 